\title{
PERAN DUKUNGAN SOSIAL DAN INTERAKSI IBU-ANAK DALAM MENINGKATKAN KESEJAHTERAAN SUBJEKTIF REMAJA PADA KELUARGA ORANG TUA BEKERJA
}

\author{
Retno Wijayanti ${ }^{\left.1^{*}\right)}$, Euis Sunarti ${ }^{2}$, Diah Krisnatuti \\ ${ }^{1}$ Program Studi IImu Keluarga dan Perkembangan Anak, Sekolah Pascasarjana, \\ IPB University, Bogor 16680, Indonesia \\ ${ }^{2}$ Departemen IImu Keluarga dan Konsumen, Fakultas Ekologi Manusia, \\ IPB University, Bogor 16680, Indonesia \\ ${ }^{\star}$ EE-mail: retno_azzam@yahoo.com
}

\begin{abstract}
Abstrak
Tingkat kesejahteraan subjektif remaja dapat digunakan untuk mengidentifikasi masalah remaja sejak dini dan membuat tindakan preventif agar terbentuk remaja yang berkualitas. Penelitian ini bertujuan menganalisis pengaruh karakteristik remaja, karakteristik keluarga, dukungan sosial, dan interaksi ibu-anak terhadap kesejahteraan subjektif remaja pada keluarga orang tua bekerja. Tempat penelitian dipilih secara purposive, yaitu Kota Depok dan desain yang digunakan adalah cross sectional study. Responden peneilitian, yaitu remaja berusia 12-18 tahun dari keluarga utuh dengan orang tua bekerja, berjumlah 120 terdiri atas 61 laki-laki dan 59 perempuan. Penarikan responden menggunakan metode disproportional stratified random sampling di lima SMP dan SMA di Kecamatan Sukmajaya, Kota Depok. Data penelitian dikumpulkan melalui self-report menggunakan kuesioner. Dukungan sosial terdiri dari dukungan instrumental, informasi, interaksi social, dan harga diri. Hasil uji beda menunjukkan bahwa dukungan sosial dimensi instrumental pada responden perempuan dan laki-laki memiliki perbedaan signifikan, sedangkan pada interaksi ibu-anak dan kesejahteraan subjektif remaja tidak ada perbedaan signifikan. Hasil uji PLS menunjukkan bahwa dukungan sosial dan interaksi ibu-anak berpengaruh langsung terhadap kesejahteraan subjektif remaja. Untuk itu orang tua hendaknya menyiapkan dukungan sosial yang sesuai bagi remaja dan membangun interaksi yang baik dengan anak diantara kesibukannya bekerja.
\end{abstract}

Kata kunci: dukungan sosial, interaksi ibu-anak, keluarga, kesejahteraan subjektif remaja, orang tua bekerja

\section{The Role of Social Support and Mother-Child Interaction on Increasing of Subjective Well-Being of Adolescents in Dual-Earner Family}

\begin{abstract}
The level of subjective well-being of adolescents can be used to identify adolescent problems early on and take preventive actions to create quality teenagers. This study aims to analyze the influence of social support, motherchild interaction on the subjective well-being of adolescents in dual-earner families. The study design used a cross-sectional study, conducted in Depok City. The example in this study is teenagers with whole families, who have working fathers and mothers, totaling 120 consisting of 61 boys and 59 girls. The sampling technique is done with disproportional stratified random sampling in five junior and senior high school in Kecamatan Sukmajaya, Depok City. Research data were collected through self-report using questionnaires. Social support consists of instrumental support, information, social interaction, and self-esteem. Different test results show that social support for the instrumental dimension of female and male respondents has significant differences, while in mother-child interaction and subjective well-being of adolescents there is no significant difference. PLS, test results show that social support and mother-child interaction have a significant direct effect on the subjective wellbeing of adolescents. So, parents prepare appropriate social support for adolescents and build a good interaction with children between their busy work.
\end{abstract}

Keywords: dual-earner, family, mother-child interaction, social support, the subjective well-being of adolescents.

\section{PENDAHULUAN}

Keluarga yang sejahtera merupakan cita-cita setiap orang. Persaingan yang tinggi untuk memperoleh sumber ekonomi berdampak pada bergabungnya suami dan istri bekerja untuk mencari nafkah keluarga (dual-earner) (Sunarti, 2013). Laporan Eksekutif Keadaan Angkatan Kerja Provinsi Jawa Barat 2018 mengungkapkan Tingkat Partisipasi Angkatan 
Kerja (TPAK) perempuan dalam tiga tahun terakhir mengalami peningkatan dengan semakin banyak perempuan yang aktif dalam sektor ekonomi. Pada tahun 2016, TPAK wanita sebesar 44,83 persen, tahun 2017 bertambah menjadi 46,39 persen dan meningkat lagi pada tahun 2018, yaitu 47,46 persen (BPS, 2018). Peningkatan pendapatan keluarga yang disebabkan peran ganda yang dimiliki ibu diharapkan mampu meningkatkan kesejahteraan anak. Seperti dinyatakan dalam penelitian Sunarti, Johan, dan Haryati (2010) yang menemukan bahwa semakin tinggi pendapatan maka semakin tinggi tingkat kesejahteraan subjektif keluarga.

Kesejahteraan remaja menjadi isu penting dalam pembangunan bangsa karena kehidupan bangsa di masa mendatang dipengaruhi oleh kualitas remaja di masa sekarang. Kesejahteraan subjektif merupakan faktor penting dalam perkembangan remaja karena dianggap mampu melindungi kesehatan mental serta mampu membuat remaja menjadi lebih kreatif, produktif dan mampu mengatasi stress dengan baik (Karaca, Karakoc, Bingol, Eren \& Andsoy, 2016). Remaja yang memiliki kesejahteraan subjektif menunjukkan sikap yang lebih empati, lebih mudah menjalin relasi sosial, bersedia berbagi, percaya diri, aktif berkegiatan, dan juga memiliki kemampuan menyelesaikan masalah dengan baik dan kreatif. Selain itu lebih sering merasakan emosi positif daripada emosi negatif, lebih sering merasakan kebahagiaan daripada ketidakbahagiaan, merasa puas karena tercapainya tujuan hidup dan lebih merasa bermakna (Veenhoven, 1988).

Remaja perempuan memiliki kesejahteraan subjektif lebih tinggi dibandingkan dengan lakilaki dan mengalami penurunan terkait usia dari remaja awal hingga remaja tengah. Penurunan kesejahteraan subjektif remaja seiring dengan bertambahnya usia remaja ditunjukkan dengan kesehatan mental dan kepuasan di sekolah (Tomyn \& Cummins, 2011). Sehubungan dengan hal tersebut, remaja sebagai generasi penerus bangsa perlu diperhatikan dan dioptimalkan kesejahteraan subjektifnya. Masa remaja adalah masa pencarian jati diri dan masa transisi dari kanak-kanak menuju dewasa. Secara fisiologis remaja adalah masa pertumbuhan dengan pengaruh hormonal yang cukup kuat sehingga memengaruhi ketidakstabilan emosinya dan rawan melakukan hal-hal negatif dalam rangka pencarian jati diri mereka (Santrock, 2011). Interaksi yang baik dengan lingkungan terdekat, yaitu orang tua, guru, dan teman sebaya sangat dibutuhkan untuk memunculkan citra diri positif akan dirinya.

Teman dan keluarga berperan dalam memberikan dukungan paling optimal bagi remaja. Bentuk dukungan sosial berupa perhatian, motivasi, informasi, interaksi positif, dan dukungan materi dari anggota keluarga atau orang lain dapat meningkatkan kualitas hidup remaja (Sherbourne \& Stewart, 1991). Dukungan sosial berpengaruh terhadap kesejahteraan subjektif karena memunculkan emosi positif, menguatkan harga diri, membangun sikap optimis, dan membantu memecahkan masalah (Cohen \& Wills, 1985). Hasil penelitian tentang dukungan sosial oleh Fan dan Lu (2020) menemukan bahwa dukungan sosial berkontribusi dalam kesejahteraan remaja. Penelitian tentang hubungan sosial selama masa remaja mengungkapkan bahwa kurangnya dukungan dan juga rendahnya persepsi dukungan sosial dari teman dan keluarga menyebabkan kesulitan kesehatan mental (Noret, Hunter \& Rasmussen, 2019).

Remaja dengan berbagai tantangan pertumbuhan dan perkembangannya, tetap membutuhkan interaksi yang tinggi dengan orang tua khususnya ibu. Hal terpenting dari interaksi ibu-anak dalam pengasuhan adalah pengawasan orang tua dalam aktivitas seharihari, keberadaannya, dan siapa teman-teman sepergaulannya. Anak yang mendapat perhatian dari orang tua akan menunjukkan rasa percaya diri lebih tinggi dan perilaku penyimpangan yang rendah dibandingkan dengan anak yang tidak mendapatkan pengawasan orang tua dalam kegiatannya (Patterson, Dishion \& Bank, 1984). Interaksi orang tua dengan anak di usia remaja terjadi perubahan karena berkembang menjadi hubungan yang lebih setara antara remaja dan orang tua dan berbeda untuk anak perempuan dan laki-laki. Kualitas interaksi ibu-anak perempuan lebih tinggi daripada anak laki-laki karena dukungan ibu kepada anak perempuan lebih besar daripada untuk anak laki-laki (Branje, Halle, Frijins \& Meeus 2010).

Remaja perempuan lebih terbuka dalam menyampaikan informasi terkait dirinya daripada remaja perempuan (Stattin \& Kerr, 2000). Interaksi remaja perempuan dengan orang tua dan teman sebaya berhubungan dengan tingkat kesejahteraan subjektif, sedangkan untuk remaja laki-laki yang berhubungan dengan kesejahteraan subjektif hanya interaksi dengan orang tua (McMahon, Creaven, \& Gallagher, 2020). 
Di era digital seperti saat ini, sedikitnya waktu interaksi anak dengan orang tua membuka peluang interaksi dengan gawai lebih intens. Kehidupan remaja terusik dengan makin maraknya remaja yang mengalami gangguan perilaku karena penyalahgunaan gawai. Menurut bank data KPAI (2016), di Kota Depok terdapat 68 kasus remaja pernah menonton pornografi dan melakukan cyber-crime, 7 kasus melakukan kejahatan seksual secara daring, 17 kasus memiliki media pornografi dari ponsel yang berbentuk video dan media lainnya.

Remaja yang menjadi korban maupun pelaku kekerasan salah satu nya sebagai dampak dari interaksi ibu-anak yang tidak memperhatikan tumbuh kembang anak. Remaja yang tidak bahagia, kesepian dan sering mengalami konflik akan menimbulkan gangguan perilaku serta bermusuhan antarremaja. Selain itu, prestasi akademiknya rendah karena kurang bisa mengikuti pelajaran di sekolah (Kaufmann et al., 2000). Fenomena kesepian, penggunaan gawai yang berlebih, dan gangguan perilaku terkait dengan remaja yang tidak bahagia merupakan tantangan yang dihadapi dalam kehidupan remaja saat ini.

Peningkatan jumlah ibu bekerja untuk menambah penghasilan keluarga menarik untuk diteliti karena akan berdampak pada kualitas interaksi dengan anak-anak dan dukungan sosial yang diterima. lbu yang bekerja pada dasarnya ingin meningkatkan kesejahteraan bagi seluruh anggota keluarga termasuk anak-anak yang bahagia, anak-anak dengan kesejahteraan subjektif yang tinggi. Dalam penelitian ini, kesejahteraan subjektif remaja diduga dipengaruhi oleh kualitas interaksi ibu-anak dan dukungan sosial yang diterimanya. Jika dukungan sosial yang diterima dan interaksi ibu-anak baik maka remaja akan merasakan kesejahteraan subjektif yang tinggi.

Ada beberapa penelitian yang dilakukan terkait dukungan sosial, interaksi ibu-anak dan kesejahteraan subjektif remaja, tetapi belum ada yang khusus pada keluarga dengan suami istri bekerja. Oleh karenanya penelitian ini bertujuan untuk mengidentifikasi karakteristik remaja dan keluarga, dukungan sosial, interaksi ibu-anak, dan kesejahteraan subjektif remaja pada keluarga orang tua bekerja; menganalisis perbedaan dukungan sosial, interaksi ibu-anak, dan kesejahteraan subjektif berdasarkan jenis kelamin remaja; dan menganalisis pengaruh kerakteristik remaja, karakteristik keluarga, dukungan sosial dan interaksi ibu-anak terhadap kesejahteraan subjektif remaja.

\section{METODE}

Desain penelitian ini adalah cross sectional study dengan lokasi penelitian dipilih secara purposive di Kota Depok. Kota Depok memiliki Indeks Pembangunan Manusia tertinggi ke-3 di Jawa Barat, yaitu 80,29 (BPS, 2018) dan Indeks Komposit Kesejahteraan Anak kategori menengah nomor 45 se-Indonesia, yaitu 76,22 (KPPPA, 2017).

Populasi penelitian adalah remaja dari keluarga utuh yang duduk di Sekolah Menengah Pertama (SMP) dan Sekolah Menengah Atas (SMA) yang memiliki ayah dan ibu bekerja di Kecamatan Sukmajaya. Responden penelitian ini adalah remaja yang dipilih dari lima sekolah dan bersedia terlibat dalam penelitian kemudian dari masing-masing sekolah dipilih siswa yang memiliki orang tua bekerja. Selanjutnya, responden dipilih secara acak (disproportional stratified random sampling) dan memeroleh responden sebanyak 61 remaja laki-laki dan 59 remaja perempuan.

Data primer yang dikumpulkan meliputi karakteristik keluarga (usia ayah, usia ibu, pekerjaan ayah, pekerjaan ibu, penghasilan keluarga, lama pendidikan ayah, lama pendidikan ibu), karakteristik remaja (usia, jenis kelamin, jumlah saudara kandung, dan urutan kelahiran), dukungan sosial, interaksi ibu-anak dan kesejahteraan subjektif remaja. Pengambilan data primer dilakukan melalui self-report yang dibantu menggunakan instrumen atau kuesioner yang telah teruji validitas dan reliabilitasnya.

Dukungan sosial adalah bantuan yang diberikan orang lain kepada seseorang berupa informasi, instrumental, interaksi sosial, dan harga diri (Cohen \& Hoberman, 1983). Kuesioner dukungan sosial yang digunakan adalah modifikasi instrumen ISEL-SF menurut Cohen dan Hoberman (1983) yang terdiri atas 16 pertanyaan yang mencakup 4 dimensi yang merupakan versi pendek. Keempat dimesi dukungan sosial tersebut adalah dukungan informasi yang merujuk pada dukungan yang dirasakan seseorang untuk mendiskusikan masalah kepentingan pribadi; dukungan instrumental yang mencakup dukungan yang dirasakan seseorang dalam bentuk bantuan materi; dukungan interaksi sosial, yaitu dukungan yang dirasakan orang lain untuk berinteraksi sosial; dan dukungan harga diri, yaitu dukungan yang dirasakan dari orang lain berupa penilaian individu terhadap kehormatan diri. Instrumen ini menggunakan 4 skala penilaian, yaitu: nilai skor 1 (sangat tidak 
setuju), 2 (tidak setuju), 3 (setuju), dan 4 (sangat setuju). Beberapa pertanyaan indifference dilakukan invers pada saat pengolahan data. Instrumen yang digunakan memiliki reliabilitas yang baik dengan Cronbach's alpha 0,748 .

Interaksi ibu-anak adalah pola perilaku dan hubungan orang tua dengan anak dalam bentuk dukungan, kehangatan, dan keberpihakan (Kenny, Dooley, \& Fitzgerald, 2013). Kuesioner interaksi ibu-anak menggunakan instrumen The Parental Authority Questionniare (Buri, 1989) yang telah diadaptasi oleh peneliti karena secara prinsip pengasuhan merupakan proses interaksi yang merupakan hubungan timbal balik antara ibuanak. Instrumen ini dimodifikasi menjadi pola interaksi, yaitu orang tua yang memberikan kebebasan dan membatasi aktifitas anak merupakan pola interaksi yang kurang baik, pertanyaan diberi tanda*) dan dilakukan invers. Pola interaksi yang baik adalah yang memberikan kesempatan pada anak dengan kontrol kuat dari ibu. Dalam kuesioner ini terdapat penyesuaian dari 30 pertanyaan menjadi 28 pertanyaan, masing-masing diberi skor 1 : sangat tidak setuju, 2 : tidak setuju, 3 : agak setuju, 4 : setuju, 5 : sangat setuju. Kuesioner ini memiliki Cronbach's alpha 0,717

Kesejahteraan subjektif merupakan suatu bentuk evaluasi secara kognitif, seperti kepuasan hidup dan afektif, seperti emosi yang positif dan negatif, mengenai kehidupan individu yang bersangkutan (Diener, Lucas, \& Scollon, 2006). Menurut Cummins, Eckersley, Pallant , Van Vugt, dan Misajon (2003) indikator kesejahteraan subjektif anak terdiri atas kepuasan rumah, kepuasan materi, kepuasan terhadap hubungan interpersonal, kepuasan terhadap area tempat tinggal, kepuasan terhadap kesehatan, kepuasan terhadap sekolah, dan kepuasan terhadap personal. Kuesioner kesejahteraan subjektif anak menggunakan intrumen dari KINDL Kiddo Questionnaires (13-16 years) menurut Stevanovic (2009) yang dimodifikasi dalam jumlah dan pengolahan data. Kuesioner awal terdiri dari 24 pertanyaan kemudian dimodifikasi menjadi 23 pertanyaan yang mencakup 6 dimensi, yaitu kesejahteraan fisik, kesejahteraan emosional, harga diri, fungsi keluarga, fungsi teman, fungsi sekolah; dengan skala penilaian semantik differensial. Skala tersusun dalam angka 1-7 dengan jawaban yang sangat positif terletak dibagian angka paling tinggi dan jawaban yang sangat negatif terletak dibagian angka paling rendah. Kuesioner ini memiliki Cronbach's alpha 0,885.
Data yang telah dikumpulkan selanjutnya diberikan skor penilaian pada setiap pernyataan kuesioner. Setelah itu, skor total dari masingmasing variabel ditransformasikan menjadi indeks. Hal ini bertujuan untuk menyamakan satuan agar perbandingan pengkategorian data setiap variabel seragam. Indeks yang dicapai dikategorikan menurut Bloom's cut-off point, yaitu rendah (indeks $0,0-60,0$ ), sedang (indeks $>60,0-80,0$ ), dan tinggi (indeks $>80,0-100,0$ ) (Yimer, Abera, Mulu, dan Bezabih 2014).

Data akan dianalisis berdasarkan tujuan penelitian. Analisis data yang dilakukan adalah (i) analisis deskriptif untuk memberikan gambaran mengenai karakteristik keluarga, karakteristik remaja, dukungan sosial, interaksi ibu-anak, dan kesejahteraan subjektif remaja; dan (ii) analisis inferensia yang digunakan sebagai analisis statistik lanjutan terdiri atas uji beda independent sample $t$-test, analisis jalur (Partial Least Square) menggunakan SmartPLS Professional untuk menganalisis pengaruh secara langsung dan tidak langsung dari karakteristik keluarga, karakteristik remaja, dukungan sosial, interaksi ibu-anak terhadap kesejahteraan subjektif remaja.

\section{HASIL}

\section{Karakteristik Keluarga}

Hasil penelitian ini memperlihatkan bahwa menurut usia, persentase terbesar ayah $(82,5 \%)$ dan ibu $(73,3 \%)$ berada pada kelompok usia madya (41-60 tahun). Hasil uji beda menunjukkan usia ayah dan ibu antara responden laki-laki dan perempuan tidak berbeda nyata. Hal ini juga ditunjukkan lebih dari separuh ayah $(65,8 \%)$ dan ibu $(54,2 \%)$ mempunyai tingkat pendidikan yang tinggi yaitu setara dengan pendidikan perguruan tinggi. Rata-rata lama pendidikan ayah 14,51 tahun sedangkan rata-rata lama pendidikan ibu 14 tahun. Hasil uji beda menunjukkan bahwa lama pendidikan ayah dan ibu antara responden lakilaki dan perempuan tidak berbeda nyata.

Hasil lain juga menunjukkan bahwa lama menikah ayah dan ibu rata-rata 19,5 tahun. Secara keseluruhan baik keluarga responden laki-laki maupun perempuan tergolong sebagai keluarga tidak miskin dengan rata-rata pendapatan perkapita sebesar Rp1.590.395.00. Ayah dari responden laki-laki lebih banyak bekerja di sektor formal $(88,5 \%)$ daripada ayah dari responden perempuan $(61,7 \%)$, meskipun secara keseluruhan dapat dikatakan bahwa sebagian besar ayah dalam penelitian ini adalah bekerja di sektor formal. 
Tabel 1 Nilai rata-rata dan uji beda karakteristik keluarga dan remaja berdasarkan jenis kelamin

\begin{tabular}{|c|c|c|c|}
\hline \multirow{2}{*}{$\begin{array}{l}\text { Karakteristik } \\
\text { keluarga }\end{array}$} & \multicolumn{2}{|c|}{ Jenis kelamin } & \multirow[b]{2}{*}{$p$-value } \\
\hline & $\begin{array}{l}\text { Laki- } \\
\text { laki }\end{array}$ & Perempuan & \\
\hline Usia ayah (tahun) & 46,15 & 48,10 & 0,065 \\
\hline Usia ibu (tahun) & 43,90 & 44,02 & 0,902 \\
\hline $\begin{array}{l}\text { Lama pendidikan } \\
\text { ayah (tahun) }\end{array}$ & 14,57 & 14,44 & 0,784 \\
\hline $\begin{array}{l}\text { Lama pendidikan } \\
\text { ibu (tahun) }\end{array}$ & 13,57 & 14,44 & 0,060 \\
\hline Besar keluarga & 4,49 & 4,63 & 0,429 \\
\hline $\begin{array}{l}\text { Pendapatan per } \\
\text { kapita (Rp ribu) }\end{array}$ & 15,47 & 16,43 & 0,684 \\
\hline $\begin{array}{l}\text { Usia remaja } \\
\text { (tahun) }\end{array}$ & 15,51 & 14,42 & $0,001^{* *}$ \\
\hline Urutan kelahiran & 1,70 & 0,70 & 0,166 \\
\hline $\begin{array}{l}\text { Jumlah saudara } \\
\text { kandung }\end{array}$ & 2,02 & 2,10 & 0,695 \\
\hline
\end{tabular}

Selanjutnya, hasil penelitian memperlihatkan bahwa persentase terbesar jenis pekerjaan ibu dari responden laki-laki adalah pekerja di sektor formal $(60,7 \%)$ sedangkan ibu dari responden perempuan lebih banyak bekerja secara informal (52,5\%). Hasil temuan penelitian ini juga menemukan bahwa lebih dari separuh keluarga responden $(53,3 \%)$ dapat dikategorikan dalam keluarga kecil dengan jumlah anggota keluarga rata-rata 4 orang.

\section{Karakteristik Remaja}

Hasil penelitian menunjukkan, rata-rata usia responden adalah 14,98 tahun. Hasil uji beda menunjukkan bahwa antara responden laki-laki dan perempuan mempunyai usia yang berbeda nyata (Tabel 1). Responden perempuan paling banyak pada usia 13 tahun, sedangkan laki-laki di usia 16 tahun. Lebih lanjut, untuk urutan kelahiran, persentase terbesar responden lakilaki $(50,8 \%)$ dan perempuan $(40,7 \%)$ adalah anak sulung. Responden laki-laki dan perempuan paling banyak mempunyai dua saudara kandung $(39,2 \%)$.

\section{Dukungan Sosial}

Hasil penelitian menyatakan, rata-rata indeks untuk dukungan sosial responden laki-laki sebesar 68,31 dan perempuan 71,12 dan dapat dikatakan masuk dalam kategori sedang. Hasil penelitian menunjukkan secara keseluruhan tidak terdapat perbedaan signifikan pada dukungan sosial antara responden laki-laki dan perempuan (Tabel 2).
Tabel 2 Nilai rata-rata capaian indeks variabel dukungan sosial berdasarkan jenis kelamin

\begin{tabular}{lcrcc}
\hline $\begin{array}{c}\text { Dimensi } \\
\text { dukungan } \\
\text { sosial }\end{array}$ & $\begin{array}{c}\text { Laki- } \\
\text { laki }\end{array}$ & Perempuan & Total & $\begin{array}{c}p \text { - } \\
\text { value }\end{array}$ \\
\hline $\begin{array}{l}\text { Dukungan } \\
\text { informasi }\end{array}$ & 68,99 & 72,74 & 70,86 & 0,130 \\
$\begin{array}{l}\text { Dukungan } \\
\text { instrumental }\end{array}$ & 67,62 & 73,31 & 70,66 & $0,045^{*}$ \\
$\begin{array}{l}\text { Dukungan } \\
\text { interaksi } \\
\text { sosial }\end{array}$ & 71,17 & 77,26 & 74,21 & 0,070 \\
$\begin{array}{l}\text { Dukungan } \\
\text { harga diri }\end{array}$ & 65,44 & 61,16 & 63,39 & 0,138 \\
\hline Total & 68,31 & 71,12 & 69,69 & 0,102 \\
\hline Keterangan: ${ }^{*}$ signifikan pada $p<0,05$ & & \\
\hline
\end{tabular}

Dimensi Informasi. Pada dimensi ini rata-rata indeksi responden perempuan lebih tinggi namun tidak ada perbedaan signifikan antara responden laki-laki dan perempuan. Hal ini disebabkan karena terbukanya kesempatan yang luas untuk setiap anak mendapatkan haknya misalnya pendidikan. Dukungan informasi yang didapatkan remaja laki-laki dan perempuan berupa nasehat seputar pelajaran di sekolah, memberikan saran ketika ada masalah, dan memberitahu bila ada kesalahan.

Dimensi Instrumental. Hasil uji beda menunjukkan bahwa dukungan pada dimensi instrumental antara responden laki-laki dan perempuan berbeda nyata ( $p$-value $=0,045$ ). Responden perempuan mendapat dukungan sosial lebih baik daripada laki-laki. Pada dimensi instrumental dukungan sosial yang diberikan berupa mengantar berobat di saat sakit, membantu melakukan pekerjaan rumah, adanya teman yang membantu ketika sedang membutuhkan sesuatu, dan mengerjakan tugas sekolah.

Dimensi Interaksi Sosial. Tabel 2 menunjukkan bahwa dimensi ini tidak terdapat perbedaan signifikan antara responden laki-laki dan perempuan. Dimensi interaksi sosial mempunyai rataan indeks paling tinggi diantara dimensi dukungan sosial lainnya. Pada dimensi interaksi sosial, dukungan sosial yang diterima responden adalah adanya teman yang menemani ketika kesepian, merasa menjadi bagian penting dalam pergaulan, seringnya bertemu, berkomunikasi, dan melakukan kegiatan bersama teman-temannya.

Dimensi Harga Diri. Dimensi harga diri mempunyai nilai rataan indeks terendah dibandingkan dimensi lainnya. $\mathrm{Hal}$ ini disebabkan karena pada usia remaja 
mengalami proses pencarian jati diri sehingga sering timbul rasa tidak percaya diri. Pada dimensi ini, meskipun tidak terdapat perbedaan signifikan tetapi responden laki-laki mempunyai nilai rataan yang lebih tinggi berupa rasa percaya diri dalam penampilan, keberhasilan dalam belajar, kepuasan hidup, dan keleluasaan dalam pergaulan.

\section{Interaksi lbu-Anak}

Data pada Tabel 3 menunjukkan, rata-rata responden memiliki indeks interaksi ibu-anak 62,82 , artinya interaksi ibu-anak berada dalam kategori sedang. Hasil uji beda menunjukkan bahwa interaksi ibu-anak antara responden laki-laki dan perempuan tidak berbeda nyata. Namun, rata-rata indeks interaksi ibu-anak pada responden laki-laki lebih tinggi dibandingkan perempuan. Hasil kajian memperlihatkan bahwa interaksi ibu-anak pada penelitian ini mempunyai indeks rendah dalam pernyataan ibu memperbolehkan anaknya mengambil keputusan sendiri dan selalu mengikuti keinginan anak. Capaian indeks yang terkategori tinggi pada pernyataan ibu selalu memberitahu alasan dibalik peraturan dan nilainilai kebaikan yang selalu ditanamkan dalam keluarga serta memberi arahan dan bimbingan dengan cara yang rasional dan obyektif.

\section{Kesejahteraan Subjektif Remaja}

Kesejahteraan subjektif diukur berdasarkan tingkat kepuasan terhadap kualitas fisik, kondisi emosi, harga diri, fungsi keluarga, teman dan sekolah. Semakin tinggi kepuasan remaja terhadap hal-hal tersebut maka mencerminkan bahwa remaja makin bahagia dengan dirinya. Hal ini berlaku sebaliknya, semakin rendah tingkat kepuasan menunjukkan semakin tidak bahagia. Hasil kajian menyatakan, rata-rata indeks untuk kesejahteraan subjektif termasuk kategori tinggi, yaitu 80,05 dan tidak ada perbedaan signifikan antara kesejahteraan subjektif pada responden laki-laki dan perempuan.

Tabel 3 Nilai rata-rata capaian indeks variabel interaksi ibu-anak berdasarkan jenis kelamin

\begin{tabular}{lccc}
\hline Variabel & Laki Laki & Perempuan & Total \\
\cline { 2 - 4 } & $\begin{array}{c}\text { Rata-rata } \\
\text { indeks }\end{array}$ & $\begin{array}{c}\text { Rata-rata } \\
\text { indeks }\end{array}$ & $\begin{array}{c}\text { Rata-rata } \\
\text { indeks }\end{array}$ \\
\hline $\begin{array}{l}\text { Min- } \\
\text { Maks }\end{array}$ & $39-101$ & $41-90$ & $39-101$ \\
$\begin{array}{l}\text { Rata- } \\
\text { rata } \pm S t d\end{array}$ & $64,22 \pm 13,88$ & $61,36 \pm 10,51$ & $62,82 \pm 12,37$ \\
\hline$p$-value & & 0,205 & \\
\hline
\end{tabular}

Tabel 4 Nilai rata-rata capaian indeks dimensi kesejahteraan subjektif remaja

\begin{tabular}{|c|c|c|c|c|}
\hline \multirow{2}{*}{$\begin{array}{l}\text { Dimensi } \\
\text { kesejahteraan } \\
\text { subjektif }\end{array}$} & $\begin{array}{l}\text { Laki- } \\
\text { laki }\end{array}$ & Perempuan & Total & \multirow[b]{2}{*}{$\begin{array}{c}p- \\
\text { value }\end{array}$} \\
\hline & $\begin{array}{l}\text { Rata- } \\
\text { rata } \\
\text { indeks }\end{array}$ & $\begin{array}{l}\text { Rata-rata } \\
\text { indeks }\end{array}$ & $\begin{array}{l}\text { Rata- } \\
\text { rata } \\
\text { indeks }\end{array}$ & \\
\hline $\begin{array}{l}\text { Kesejahteraan } \\
\text { fisik }\end{array}$ & 82,59 & 79,69 & 81,17 & 0,291 \\
\hline $\begin{array}{l}\text { Kesejahteraan } \\
\text { emosi }\end{array}$ & 80,52 & 76,56 & 78,58 & 0,225 \\
\hline Harga diri & 78,11 & 76,05 & 77,10 & 0,487 \\
\hline $\begin{array}{l}\text { Fungsi } \\
\text { keluarga }\end{array}$ & 83,39 & 81,07 & 82,25 & 0,317 \\
\hline Fungsi teman & 82,70 & 82,85 & 82,78 & 0,959 \\
\hline $\begin{array}{l}\text { Fungsi } \\
\text { sekolah }\end{array}$ & 78,14 & 79,11 & 78,51 & 0,759 \\
\hline Total & 80,96 & 79,11 & 80,05 & 0,365 \\
\hline
\end{tabular}

Kesejahteraan Fisik responden laki-laki memiliki nilai rataan indeks lebih tinggi dibandingkan perempuan. Remaja laki-laki merasa sehat, kuat dan penuh energi, serta tidak lelah dan mengantuk dibandingkan responden perempuan.

Harga Diri. Dimensi harga diri mempunyai indeks terendah dibandingkan dimensi lain dan tidak ada perbedaan nyata antara responden laki-laki dan perempuan. Dimensi harga diri dilihat dari perasaan bangga pada diri sendiri, mempunyai ide-ide yang baik, bahagia, dan sukses dalam belajar.

Fungsi Keluarga. Hasil penelitian menunjukkan bahwa responden laki-laki memiliki rataan indeks lebih tinggi daripada perempuan. Hal ini menunjukkan bahwa responden laki-laki merasa lebih puas terhadap hubungan dengan keluarganya dibandingkan dengan responden perempuan.

Fungsi Teman. Secara umum, fungsi teman merupakan dimensi dari kesejahteraan subjektif yang memiliki rata-rata indeks tertinggi dibandingkan dimensi kesejahteraan subjektif lainnya yaitu 82,78. Kepuasan responden terhadap fungsi teman yang dirasakan adalah ketika melakukan kegiatan bersama teman-teman serta bisa bergaul dengan baik karena teman selalu mendukung dalam meraih prestasi.

Fungsi Sekolah. Hasil memperlihatkan rataan indeks responden perempuan $(79,11)$ lebih tinggi dibandingkan laki-laki $(78,14)$ pada dimensi ini. Responden perempuan merasa lebih mampu mengerjakan tugas-tugas sekolah dengan baik, senang disekolah dan optimis terhadap masa depan. 


\section{Faktor-faktor yang Memengaruhi Kesejahteraan Subjektif Remaja}

Dukungan sosial $\quad(\beta=0,531, \quad t>1,96)$ berpengaruh langsung secara positif terhadap kesejahteraan subjektif remaja, artinya remaja yang mendapat dukungan dari lingkungan sekitar akan merasa dihargai, diperhatikan, serta dicintai sehingga merasa bahagia. Dukungan sosial dimensi informasi mempunyai pengaruh paling kuat terhadap dukungan sosial secara umum dengan nilai outer loading $\beta=0,849, t>1,96$. Interaksi ibu-anak $(\beta=0,274$, $t>1,96$ ) juga berpengaruh langsung secara positif terhadap kesejahteraan subjektif remaja. Artinya, orang tua yang memberikan perhatian, arahan, dan memahami kebutuhan remaja maka akan merasa bahagia dan puas.

Dimensi kesejahteraan emosi memengaruhi kesejahteraan subjektif remaja paling kuat $(\beta=0,805, \quad t>1,96)$. Variabel karakteristik keluarga yang menjadi variabel endogen model adalah lama pendidikan ayah dan ibu (Gambar 1). Hal ini terlihat dari nilai outer loading nya $>0,5$ yaitu sebesar 0,983 untuk lama pendidikan ayah dan 0,770 untuk lama pendidikan ibu. Analisis lebih lanjut (Tabel 5), variabel tersebut dapat memengaruhi kesejahteraan subjektif remaja secara tidak langsung melalui interaksi ibu-anak. Peningkatan lama pendidikan orang tua akan menyebabkan peningkatan interaksi dan akhirnya meningkatkan kesejahteraan subjektif remaja.

\begin{tabular}{|c|c|c|c|c|}
\hline Tabel 5 & $\begin{array}{l}\text { Hasil } \\
\text { karał } \\
\text { karał } \\
\text { sosia } \\
\text { terha } \\
\text { rema }\end{array}$ & $\begin{array}{l}\text { dekor } \\
\text { eristik } \\
\text { eristik } \\
\text { dan } \\
\text { ap kes } \\
\text { a }\end{array}$ & $\begin{array}{l}\text { isi } \\
\text { aja, o } \\
\text { raksi } \\
\text { eraan }\end{array}$ & $\begin{array}{l}\text { engaruh } \\
\text { eluarga, } \\
\text { ukungan } \\
\text { bu-anak } \\
\text { subjektif }\end{array}$ \\
\hline \multirow{3}{*}{ Kategori } & \multicolumn{4}{|c|}{ Kesejahteraan subjektif remaja } \\
\hline & \multirow[t]{2}{*}{$\mathrm{DE}$} & \multicolumn{2}{|c|}{ IE melalui } & \multirow[t]{2}{*}{ TE } \\
\hline & & DS & ITR & \\
\hline $\begin{array}{l}\text { Karakteristik } \\
\text { keluarga }\end{array}$ & 0,023 & 0,037 & 0,080 & 0,093 \\
\hline $\begin{array}{l}\text { Karakteristik } \\
\text { remaja }\end{array}$ & 0,123 & $0,112^{*}$ & $0,144^{*}$ & 0,072 \\
\hline $\begin{array}{l}\text { Dukungan } \\
\text { sosial }\end{array}$ & 0,531 & - & & $0,531^{* *}$ \\
\hline $\begin{array}{l}\text { Interaksi ibu- } \\
\text { anak }\end{array}$ & 0,314 & $0,182^{*}$ & . & 0,132 \\
\hline $\mathrm{R}^{2}$ & & & 249 & \\
\hline Adj. $\mathrm{R}^{2}$ & & & 223 & \\
\hline $\mathrm{N}$ & & & 20 & \\
\hline
\end{tabular}

Keterangan: ${ }^{* *}$ signifikasi pada $t>1,96 \quad p$-value $<0,050$; *signifikasi pada $p$-value $<0,01 ; \mathrm{DE}=$ direct effect, $\mathrm{IE}=$ indirect effect; TE=total effect; DS=dukungan sosial; ITR=interaksi ibu-anak
Berdasarkan analisis smart PLS mengenai pengaruh model karakteristik keluarga, karakteristik angka $R$-square 0,249 , yang menjelaskan bahwa 24,9 persen model variabel-variabel memengaruhi kesejahteraan subjektif remaja, dan sisanya 75,1 persen dipengaruhi oleh variabel lain di luar penelitian.

\section{PEMBAHASAN}

Pada penelitian ini kesejahteraan subjektif remaja tergolong tinggi dengan dimensi fungsi teman dan fungsi keluarga sebagai dimensi dengan indeks lebih tinggi dibandingkan dimensi lainnya. Hasil tersebut sesuai dengan penelitian yang dilakukan oleh Crivello, Camfield, dan Woodhead (2009) yang menemukan bahwa kualitas hubungan sosial dengan keluarga dan kelompok sebaya menjadi faktor penting untuk kesejahteraan subjektif remaja. Pada dimensi fungsi sekolah, responden perempuan mempunyai indeks lebih tinggi daripada laki-laki. Dalam penelitian yang dilakukan oleh Al-Attiyah dan Nasser (2016) juga menyebutkan bahwa anak laki-laki kurang puas dibandingkan anak perempuan di sekolah karena anak laki-laki lebih sering memiliki hubungan buruk dengan teman sekelas dan lebih senang dengan kebebasan. Van De Wetering, Van Exel, dan Brouwer (2010) menemukan bahwa anak perempuan lebih bahagia di sekolah sementara anak laki-laki cenderung lebih bahagia di rumah dan selama waktu luang mereka.

Hasil uji beda menunjukkan bahwa kesejahteraan subjektif antara responden lakilaki dan perempuan tidak berbeda nyata. Pada penelitian lain dilaporkan untuk mencapai kesejahteraan, perempuan dan laki-laki memiliki upaya yang berbeda. Menurut Leung, McBride-Chang, dan Lai (2004), laki-laki melakukan kegiatan aktif dalam mengisi waktu luang dan mencoba tidak memikirkan pikiran yang tidak diinginkan dalam mencapai kebahagiaan. Sementara itu, perempuan lebih memilih menjalin hubungan sosial atau pertemanan, menyelesaikan studi atau mengejar karir serta kegiatan pasif pengisi waktu luang (menonton televisi, menyewa video, berbelanja), dan menjalankan kegiatan keagamaan untuk mencapai kebahagiaan.

Selanjutnya, penelitian ini menegaskan bahwa kesejahteraan subjektif remaja dipengaruhi oleh dukungan sosial dan interaksi ibu-anak. Maknanya, semakin besar dukungan sosial yang diterima serta terbentuknya interaksi yang positif dengan orang tua maka akan semakin tinggi tingkat kesejahteraan subjektif remaja. 


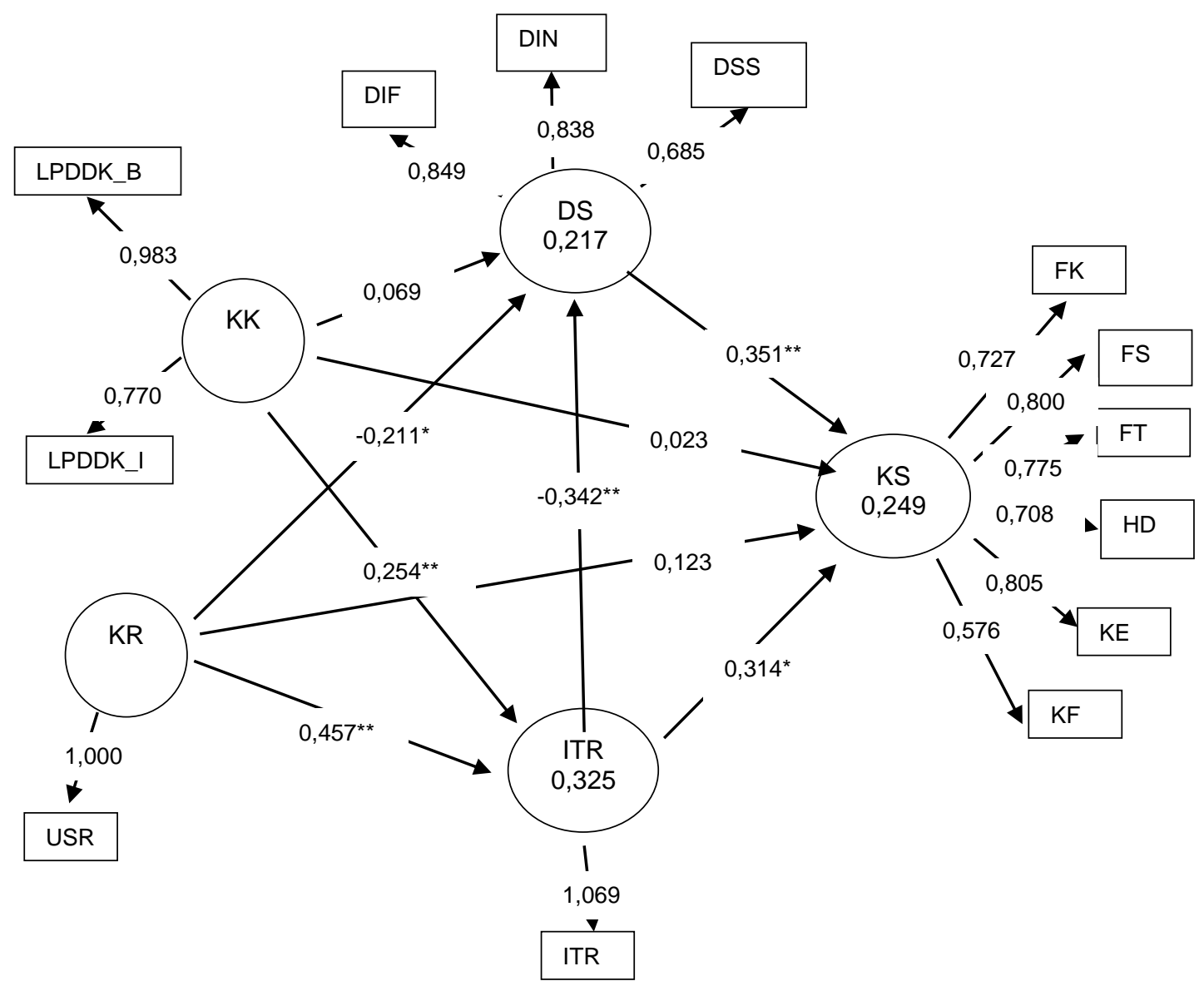

Keterangan:

\begin{tabular}{|c|c|}
\hline $\begin{array}{l}\text { KK } \\
\text { LPDDK_B } \\
\text { LPDDK_I } \\
\text { KR } \\
\text { USA } \\
\text { DS } \\
\text { DIF } \\
\text { DIN } \\
\text { DSS }\end{array}$ & $\begin{array}{l}=\text { karakteristik keluarga } \\
=\text { lama pendidikan ayah } \\
=\text { lama pendidikan ibu } \\
=\text { karakteristik remaja } \\
=\text { usia anak } \\
=\text { dukungan sosial } \\
=\text { dukungan informasi } \\
=\text { dukungan instrumental } \\
=\text { dukungan interaksi sosial }\end{array}$ \\
\hline
\end{tabular}

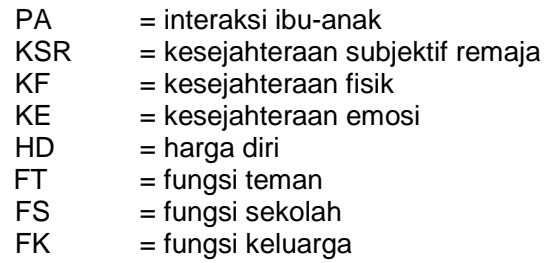

Gambar 1 Model akhir pengaruh karakteristik keluarga, karakteristik remaja, dukungan sosial, dan interaksi ibu-anak terhadap kesejahteraan subjektif remaja

Kajian terkait dukungan sosial yang dilakukan oleh Lavasani, Borhanzadeh, Afzali, dan Hejazi (2011) mengungkapkan bahwa orang tua yang berperan mendukung anak-anak menunjukkan hubungan yang signifikan terhadap kesejahteraan psikologis sehingga anak-anak akan mampu melewati masa krisis di usia remaja.

Dukungan sosial berpengaruh positif terhadap kesejahteraan subjektif remaja, artinya semakin besar dukungan yang diterima maka kesejahteraan subjektif yang dirasakan semakin baik. Dalam penelitian ini dukungan yang diberikan berupa bantuan dan kehadiran disaat ada masalah, menemani disaat bahagia dan sedih serta teman menjadi tempat mencurahkan perasaan bila menghadapi masalah. Hasil penelitian yang sama diungkapkan oleh Frey dan Stutzer (2010) yang menyatakan bahwa semakin tinggi jumlah teman dekat yang dimiliki anak dan semakin banyak orang tua menghabiskan waktu dan berbicara dengannya, anak merasa lebih bahagia. Kualitas kehidupan seseorang dipengaruhi oleh persepsi tentang dukungan yang diterima baik dari keluarga, teman, dan orang lain. Hasil penelitian tentang dukungan sosial juga disampaikan oleh Furman dan Sibthorp (2013), selama masa remaja teman dekat mempunyai pengaruh besar sebagai sumber utama dukungan sosial remaja melebihi orang tua dan berkontribusi dalam kesejahteraan remaja. Hasil yang sama 
didapatkan dari penelitian yang dilakukan oleh Situmorang dan Latifah (2014) bahwa dukungan sosial berpengaruh tidak langsung terhadap prestasi akademik melalui strategi pengaturan diri dalam belajar paling besar dirasakan oleh anak berasal dari teman.

Hasil penelitian ini juga menunjukkan bahwa dukungan sosial yang diterima remaja termasuk kategori sedang. Dukungan sosial merupakan kebutuhan mendasar bagi individu untuk melanjutkan hubungan sosial, mengatasi kesepian, beradaptasi dengan teman-teman dan mempertahankan stabilitas psikologis (Gunuc \& Dogan, 2013). Hasil uji beda menunjukkan bahwa pada dimensi instrumental ada perbedaan yang nyata antara responden laki-laki dan perempuan. Hal ini sesuai dengan penelitian yang dilakukan oleh Tam (2011) yang menemukan bahwa dukungan sosial dirasakan berbeda oleh anak laki-laki dan perempuan karena anak laki-laki secara psikologis berbeda dengan anak perempuan sehingga memengaruhi dalam pergaulan dengan teman-temannya. Pada penelitian ini responden perempuan lebih membutuhkan bantuan teman atau keluarga seperti mengantarkan ke dokter bila sakit dan membantu pekerjaan rumah sehingga indeks rata-rata yang diperoleh responden perempuan pada dimensi dukungan instrumental lebih tinggi daripada responden laki-laki. Penelitian lain dilaporkan anak perempuan memiliki teman lebih sedikit tetapi mempunyai hubungan lebih erat, sedangkan laki-laki memiliki teman banyak hanya hubungannya tidak erat (Bryant, 1994).

Sementara itu, interaksi ibu-anak dalam penelitian ini juga berpengaruh positif terhadap kesejahteraan subjektif remaja. Artinya, anak semakin merasakan kebahagiaan bila semakin baik kualitas interaksinya dengan ibu. Interaksi ibu-anak yang memberikan perhatian, arahan, menerima kondisi anak disertai memberikan batasan aturan dengan otoritas tinggi melalui penjelasan, pemahaman, keinginan, tujuan, dan pengetahuan dianggap positif membantu remaja menyelesaikan tugas perkembangannya dan dalam pengembangan potensinya (Dehyadegary, Yaacob, Juhari, \& Talib, 2012). Hasil dari penelitian yang dilakukan oleh Talib, Mohamad, dan Mamat (2011) juga menunjukkan bahwa perilaku dan prestasi anak dipengaruhi interaksi ibu-anak yang baik dan responsif. Kualitas hubungan orang tua dan anak berkaitan dengan kesejahteraan anak (Quilgars, Searle, Keung, \& Mayhew, 2005). Dalam serangkaian analisa penelitian yang dilakukan oleh Leung dan Leung (1992) menemukan bahwa hubungan dengan orang tua mendominasi prediksi kepuasan hidup remaja disamping kemampuan sosial dan konsep diri.

Interaksi ibu-anak pada penelitian ini termasuk kategori sedang. Peran ganda yang dimiliki perempuan bekerja selain berdampak positif juga memiliki dampak negatif yaitu semakin menambah persoalan kehidupan dalam pekerjaan dan keluarga. Seperti disampaikan dalam penelitian yang dilakukan oleh Van Daalen, Willemsendan Sanders (2006) yang menemukan bahwa tanggung jawab ganda antara keluarga dan pekerjaan membuat berkurangnya interaksi bersama anak-anak sehingga berdampak pada berkurangnya perhatian, bimbingan, dan penjelasan atas setiap tindakan pada anak. Hal berbeda diungkapkan oleh Bee dan Boyd (2004) yang mengungkapkan bahwa tekanan yang dialami ibu dalam menjalankan pekerjaannya mengakibatkan hubungan yang kurang hangat dengan penerapan disiplin yang tinggi. Ibu tipe ini menganggap disiplin yang tinggi adalah sesuatu yang positif bagi perkembangan remaja. Dalam interaksi ibu-anak tidak ditemukan adanya perbedaan signifikan antara responden laki-laki dan perempuan. Artinya, responden laki-laki dan perempuan mempunyai kesempatan yang sama untuk berinteraksi dan menjalin hubungan baik dengan ibu.

Lama pendidikan ayah dan ibu dapat memengaruhi kesejahteraan subjektif remaja secara tidak langsung melalui interaksi ibuanak. Temuan ini menunjukkan bahwa peningkatan lama pendidikan orang tua akan menyebabkan peningkatan interaksi dan akhirnya meningkatkan kesejahteraan subjektif remaja. Studi yang dilakukan oleh Gohm, Oishi, Darlington, dan Diener (1998) menemukan bahwa pada masa remaja kepuasan hidup sangat dipengaruhi oleh pengalaman hidup dan hubungan khususnya dalam konteks dengan keluarga. Diener et al. (2006) mengatakan bahwa faktor demografi, yaitu pendapatan, status pernikahan, status pekerjaan, usia jenis kelamin, pendidikan, jumlah anak dan kegiatan beragama mempunyai dampak terhadap kesejahteraan subjektif seseorang.

\section{SIMPULAN DAN SARAN}

Dukungan sosial paling tinggi yang diterima responden adalah dukungan interaksi sosial sedangkan dukungan harga diri memiliki capaian terendah. Dukungan informasi memberikan kontribusi paling besar terhadap dukungan sosial yang diterima remaja. Dukungan instrumental yang diterima 
responden perempuan lebih tinggi dibandingkan dengan laki-laki. Variabel interaksi ibu-anak dan kesejahteraan subjektif remaja tidak ditemukan adanya perbedaan antara responden laki-laki dan perempuan artinya di dalam keluarga, anak laki-laki dan perempuan mempunyai kualitas yang sama dalam berinteraksi dengan ibu dan mendapatkan kebahagiaan. Kesejahteraan subjektif remaja dipengaruhi secara tidak langsung oleh lama pendidikan ayah dan ibu melalui interaksi ibu-anak.

Berdasarkan hasil penelitian yang menemukan pengaruh interaksi ibu-anak terhadap kesejahteraan subjektif remaja, maka bagi para ibu diharapkan bisa meningkatkan kualitas interaksi dengan anak dan memberikan dukungan dengan cara bersikap sebagai teman yang bisa menjadi tempat bercerita, bersikap lebih terbuka untuk berdiskusi demi kepentingan terbaik anak diantara kesibukannya bekerja. Bagi para praktisi keluarga yang bergerak dibidang pemberdayaan masyarakat diharapkan membantu menciptakan program pemberdayaan komunitas remaja seperti PIK-R (Pusat Informasi dan Konseling Remaja) untuk melatih remaja sebagai konselor sebaya, agar remaja memperoleh informasi yang baik dalam menghadapi masalahnya. Bagi pemerintah daerah peneliti merekomendasikan adanya pembangunan wilayah ramah keluarga, yaitu pembangunan yang menjadikan kota memiliki daya tampung alam dan lingkungan, sarana dan prasarana infrastruktur yang memungkinkan keluarga memperoleh pekerjaan sehingga meningkatkan waktu interaksi dengan keluarga. Keterbatasan penelitian ini adalah interaksi yang diteliti hanya antara ibu dan anak serta menggunakan pertanyaan tertutup, maka penelitian selanjutnya diharapkan untuk melibatkan ayah sebagai responden serta melakukan wawancara untuk menggali informasi lebih mendalam.

\section{DAFTAR PUSTAKA}

[BPS] Badan Pusat Statistika Provinsi Jawa Barat. (2018). Laporan Eksekutif Keadaan Angkatan Kerja Provinsi Jawa Barat Februari 2018. Jawa Barat, ID: BPS.

[KPAI] Komisi Perlindungan Anak Indonesia. (2016). Data Kasus Perlindungan Anak Berdasarkan Lokasi Pengaduan dan Pemantauan Media Se-Indonesia Tahun 2011-2016. Jakarta, ID: KPAI
[KPPPA] Kementerian Pemberdayaan Perempuan dan Perlindungan Anak. (2017). Indeks Komposit Kesejahteraan Anak Kabupaten/Kota 2017. Jakarta, ID: KPPA.

Al-Attiyah, A., \& Nasser, R. (2016). Gender and age differences in life satisfaction within a sex-segregated society: Sampling youth in Qatar. International Journal of Adolescence and Youth, 21(1), 84-95. doi:10.1080/02673843.2013.808158.

Bee, H., \& Boyd, D. (2004). The development of social relationships. The developing child, 267-294.

Branje, S. J. T., Hale III, W. W., Frijns, T., \& Meeus, W. H. J. (2010). Longitudinal associations between perceived parentchild relationship quality and depressive symptoms in adolescence. Journal Abnormal Child Psychology, 2010(38), 751-763. doi:10.1007/s10802010- 9401-6.

Buri, J. R. (1989). An instrument for the measurement of parental authority prototypes. Washington.D.C, US: Institute of Education Science.

Cohen, S., \& Hoberman, H. M. (1983). Positive events and social supports as buffers of life change stress1. Journal of applied social psychology, 13(2), 99-125. doi:10.11111/j.1559-1816-1983.tb02325.x.

Cohen, S., \& Wills, T. A. (1985). Stress, social support, and the buffering hypothesis. Psychological bulletin, 98(2), 310. doi:10.1037/0033-2909.98.2.310.

Crivello, G., Camfield, L., \& Woodhead, M. (2009). How can children tell us about their wellbeing? Exploring the potential of participatory research approaches within young lives. Social indicators research, 90(1), 51-72. doi:10.1007/ s11205-008-9312-x.

Cummins, R. A., Eckersley, R., Pallant, J., Van Vugt, J., \& Misajon, R. (2003). Developing a national index of subjective wellbeing: The Australian Unity Wellbeing Index. Social indicators research, 64(2), 159-190.

Dehyadegary, E., Yaacob, S. N., Juhari, R. B., \& Talib, M. A. (2012). Relationship between parenting style and academic achievement among Iranian adolescents in Sirjan. Asian Social Science, 8(1), 156-160. doi:10.5539 /ass.v8n1p156. 
Diener, E., Lucas, R. E., \& Scollon, C. N. (2006). Beyond the hedonic treadmill: Revising the adaptation theory of wellbeing. American Psychologist, 61(4), 305314. doi:10.1037/0003-066X.61.4.305.

Fan, X., \& Lu, M. (2020). Testing the effect of perceived social support on left-behind children's mental well-being in mainland China: The mediation role of resilience. Children and Youth Services Review, 109, 104-695. doi:10.1016/ j.childyouth.2019.104695.

Frey, B. S., \& Stutzer, A. (2010). Happiness and economics: How the economy and institutions affect human well-being. New Jersey, US: Princeton University Press.

Furman, N., \& Sibthorp, J. (2013). The development of prosocial behavior in adolescents: A mixed methods study from NOLS. Journal of Experiential Education, 20(10), 1-16. doi:10.1177/105382 5913489105.

Gohm, C. L., Oishi, S., Darlington, J., \& Diener, E. (1998). Culture, parental conflict, parental marital status, and the subjective well-being of young adults. Journal of Marriage and the Family, 319-334. doi:10.2307/353851.

Gunuc, S. \& Dogan, A. (2013). The relationship between Turkish adolescents, internet addiction, their perceived social support and family activities. Computers in Human Behavior, 29(6), 2197-2207. doi:10.1016/ j.chb.2013.04.011.

Karaca, S., Karakoc, A., Bingol, F., Eren, N., \& Andsoy, I. I. (2016). Comparison of subjective wellbeing and positive future expectations in between working and nonworking adolescents in Turkey. Iranian Red Crescent Medical Journal, 18(2). doi:10.5812/ircmj.21055.

Kaufmann, D., Gesten, E., Santa, Lucia, R. C., Salcedo, O., Rendina-Gobioff, G., \& Gadd, R. (2000). The relationship between parenting style and children's adjustment: The parents' perspective. Journal of Child and family studies, 9(2), 231-245. doi:10.1023/A1009475122883.

Kenny, R., Dooley, B., \& Fitzgerald, A. (2013). Interpersonal relationships and emotional distress in adolescence. Journal of adolescence, 36(2), 351-360. doi:10.1016 /j.adolescence.2012.12.005.

Lavasani, M. G, Borhanzadeh, S., Afzali, L., \& Hejazi, E. (2011). The relationship between perceived parenting styles, social support with psychological well-being. ProcediaSocial and Behavioral Sciences, 15 (2011), 1852-1856. .2011.04.014.

Leung, C. Y. W., McBride-Chang, C., \& Lai, B. P. Y. (2004). Relations among maternal parenting style, academic competence, and life satisfaction in Chinese early adolescents. The Journal of Early Adolescence, 24(2), 113-143. doi:10.1177/ 0272431603262678.

Leung, J. P., \& Leung, K. (1992). Life satisfaction, self-concept, and relationship with parents in adolescence. Journal of Youth and adolescence, 21(6), 653-665. doi:10.1007/bf01538737.

McMahon, G., Creaven, A. M., \& Gallagher, S. (2020). Stressful life events and adolescent well-being: The role of parent and peer relationships. Stress and Health. doi:10.1002/smi.2923.

Noret, N., Hunter, S. C., \& Rasmussen, S. (2019). The role of perceived social support in the relationship between being bullied and mental health difficulties in adolescents. School Mental Health, 1-13. doi:10.1007/s12310-019-09339-9..

Patterson, G. R., Dishion, T. J., \& Bank, L. (1984). Family interaction: A process model of deviancy training. Aggressive behavior, 10(3), 253-267.

Quilgars, D., Searle, B. A., Keung, A., \& Mayhew, E. (2005). Mental health and well-being: In J. Bradshaw (Ed.), The Wellbeing of Children in the UK (2nd ed., pp. 134-160). London, UK: Save the Children UK.

Santrock, J. W. (2011). Life-span development perkembangan masa hidup edisi kelima. Jakarta, ID: Penerbit Erlangga.

Sherbourne, C.D., \& Stewart, A.L. (1991). The MOS social support survey. Social science \& medicine, 32(6), 705-714. doi:10.1016/0277-9536(91)90150-B.

Situmorang, Z. R. D., \& Latifah, M. (2014). Pengaruh dukungan sosial, konsep diri, dan strategi pengaturan diri dalam belajar terhadap prestasi akademik. Jurnal IImu Keluarga \& Konsumen, 7(3), 154-163. doi:10.24156/jikk.2014.7.3.154.

Stevanovic, D. (2009). Serbian KINDL questionnaire for quality of life assessments in healthy children and adolescents: Reproducibility and construct validity. Health and quality of life 
outcomes, $7(1), \quad 79 . \quad$ doi:10.1186/14777525-7-79.

Sunarti, E. (2013). Potret ketahanan keluarga indonesia perspektif keragaman pola nafkah keluarga. Jakarta, ID: BKKBN.

Sunarti, E., Johan, I. R, \& Haryati, C. (2010). Hubungan fungsi agil dengan kesejahteraan keluarga nelayan yang rawan terkena bencana alam. Jurnal IImu Keluarga \& Konsumen, 3(1), 11-17. doi:10.24156/jikk.2016.3.1.11.

Talib, J., Mohamad, Z., \& Mamat, M. (2011). Effects of parenting style on children development. World Journal of Social Sciences, 1(2), 14-35.

Tomyn, A. J., \& Cummins, R. A. (2011). The subjective wellbeing of high-school students: Validating the personal wellbeing index-school children. Social Indicators Research, 101(3), 405-418. doi:10.1007/ s11205-010-96686-9.

Van De Wetering, E. J., Van Exel, N. J. A., \& Brouwer, W. B. F. (2010). Piecing the jigsaw puzzle of adolescent happiness. Journal of Economic Psychology, 31(6), 923-935. doi:10.1016/j .joep.2010.08.004.

Veenhoven, R. (1988). The utility of happiness. Social indicators research, 20(4), 333-354.

Yimer, M., Abera, B., Mulu, W., \& Bezabih, B. (2014). Knowledge, attitude and practices of high risk populations on louse-borne relapsing fever in Bahir Dar city, north-west Ethiopia. Science Journal of Public Health, 2(1), 15-22. doi:10.11648/j.sjph .20140201.13. 